\title{
SIGILLATAS HISPÁNICAS CON GRAFFITI
}

\author{
HISPANIC SIGILLATAS WITH INSCRIPTION
}

\author{
JOSEP MONTESINOS I MARTÍNEZ \\ Universitat de València
}

Realizamos aquí el estudio de cuatro piezas de terra sigillata con inscripción. De las mismas una primera y somera exposición centrada en la parte lingüística y filológica ha sido presentada recientemente por Ballester y Turiel (2013). Las piezas fueron localizadas en el llamado mercado de antigüedades por Don Max Turiel, quien las adquirió, depositándolas inmediatamente como donación en la Real Academia de la Historia, en Madrid, y donde, cuando escribimos esto, se hallan custodiadas a la espera de su definitiva catalogación' 1 .

Sobre las superficies cerámicas aparecen con cierta frecuencia grafitos realizados por sus propietarios o por sus usuarios. En ocasiones son unas simples e indescifrables marcas; en otras, grafismos latinos con significado. Se tiende a pensar que indican propiedad de uso, una forma de identificar la propia vajilla, plato o vaso. También en ocasiones son señas que indican marcas de hornada, de piezas almacenadas e identificadas para su envío... Sin lugar a dudas estos restos, estas muestras de vida, hacen visible la lengua viva de su tiempo. Naturalmente, una vez rota o resquebrajada una sigilata, no puede descartarse el uso escriturario de un fragmento con fines distintos a la marca de propietario o usuario.

\section{1)}

Fragmento de plato, con pared curva, de 6'4 x $2 \mathrm{~cm}$. Pasta rosácea (L33) ${ }^{2}$, ligeramente granulosa; barniz

1. Las fotografías de tres de las cuatro piezas aquí presentadas fueron realizadas en el Laboratorio de Arqueología de la Universidad de Valencia. Conste igualmente nuestro agradecimiento al Departamento de Arqueología y Prehistoria de la Universidad de Valencia por permitirnos la realización de dichas fotografías y muy especialmente al autor de las mismas, Don Lluís Molina. La fotografía de la pieza que presentamos bajo el número 2 es de autoría anónima.

2. Para la identificación de colores hemos utilizado A. Cailleux: Notice sur le code des couleurs des sols, Boubée, Bondel imp. marrón rojizo de buena calidad (R20) más oscuro en la zona interior del plato.

Se trata de un fragmento de Terra Sigillata Hispanica, probablemente de la forma 18. De excelente calidad, en barniz especialmente, muy próximo a los productos gálicos. El fragmento está roto por debajo del borde y en el cambio de plano de la pared hacia el fondo. Nos inclinamos por identificarlo como un producto hispánico fundamentalmente por las características de la pasta, granulosa y no tan depurada como en los productos de las Galias.

Dada la calidad del producto, bien pudiera adjudicarse a la producción temprana de la industria de Tritium Magallum. Dicha producción tiene unos perfiles en esta forma muy próximos a los homólogos del sur de las Galias (Mayet, 1983-84, II, Pl. LXI, especialmente del 50 al 52). En los talleres del sur de las Galias la forma 18 florece en el reinado de Claudio, continuando en los siguientes emperadores, hasta la época de Domiciano-Trajano en que pasa a convertirse en la forma Dragendorff 18/31 (Oswald y Pryce, 1920, 18-183).

Sin embargo este tipo 18 no es abundante entre la producción hispánica. Se identifica su producción dentro de los alfares de Tritium Magallum, en concreto en el centro de Bezares (Garabito, 1978, 60-61). En cuanto a la difusión de la forma hispánica, esta se localiza en Italica, Osuna, Córdoba, Almedinilla, Conimbriga (Delgado, Mayet y Mountinho, 1975, 228-230, Pl. XLVIII,), Pamplona (Mezquíriz, 1958, 113, Fig. 42, núm. 17), Valentia, Saguntum, Ilici (Montesinos, 1991, fig. 46 y fig. 25; 1998, fig. 59, núm. 68). Además de tres piezas que entrarían en el tipo aquí tratado, con perfil curvo muy semejante a lo gálico, en el museo de Vila Viçosa en Portugal con sello de SELEIESI·FI, otro en el Museo Arqueológico Nacional de Madrid procedente de Belo. Nuestra pieza es muy semejante a dos de las procedentes de Viçosa y Belo, su pared curva antes del cambio de plano hacia el fondo, mide $2 \mathrm{~cm}$, exactamente lo que mide la que aquí tratamos (Mayet, 1983-84, II, Pl. LXI, 5052). 


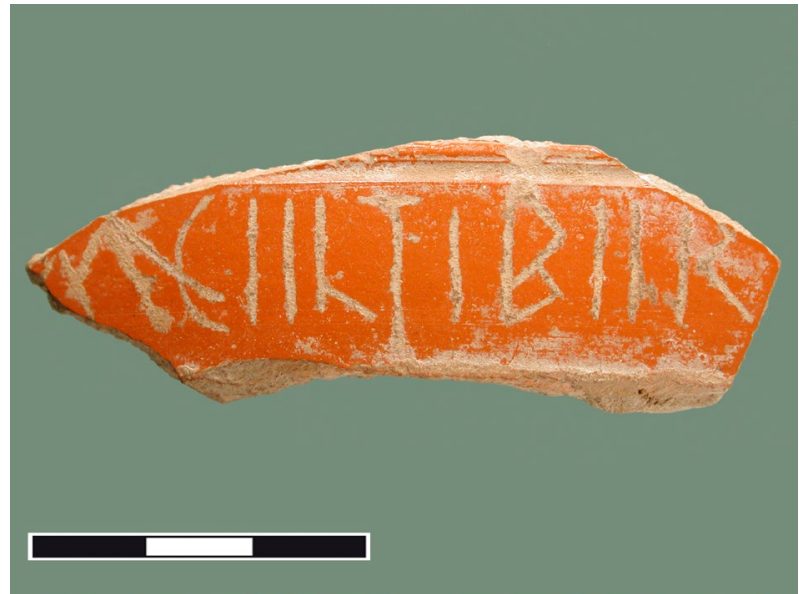

Figura 1: Fragmento de cerámica con grafito CELTIBER.

Los tipos hispánicos imitan aquellos gálicos del período de los flavios (Mayet, 1983-84, I, 71). No obstante los siguientes productos hispánicos tienden más a un perfil menos curvo. Nos encontramos, pues, ante un producto hispánico probablemente tritiense y con una cronología flavia, del 69 al 96 d.C. Es por ello que el presente fragmento en nuestra opinión no rebasa dicho siglo, situándolo con toda probabilidad en el último cuarto del primer siglo de nuestra Era.

En la parte exterior de la pared grafito inciso:

\section{CELTIBER}

Respecto a la lectura resulta, desde luego, sospechoso que el fragmento esté precisamente alrededor del nombre completo, por lo que, salvo que la inscripción sea falsa, debió de realizarse después de la fractura. No es la primera vez que aparecen nombres de referencia geográfica en grafitos sobre sigillata hispánica. Así tenemos por ejemplo un GALLI en Complutum (en el fondo externo de una pieza Hispánica forma 37 decorada, Rascón et alii, 1994, 250, fig. p. 253, nº. 24). Los cognomina geográficos indican lugar de origen del propietario, aunque también pasan de padres a hijos sin que forzosamente vivan las generaciones posteriores en el lugar al que hace referencia el topónimo.

Como señala Lorrio $(2011,59)$, el antropónimo Celtiber aparece «siempre fuera del territorio celtibérico conocido por otras fuentes documentales»y, como en el caso de Celtius, «estos antropónimos contribuyen a definir por exclusión el área propiamente céltica y/o celtibérica, por cuanto se ha considerado que estas denominaciones corresponden a individuos no autóctonos, pues debían servir como elemento caracterizador de los mismos e indicador de su origen [...] además de contribuir a la definición en negativo del área céltica, ponen de relieve las zonas de emigración de las gentes célticas» (Lorrio, 2011, 59).

\section{2)}

Fragmento de vaso de Terra Sigillata Hispanica con decoración, de la forma 37, de 8'1 x 6'5 cm. Pasta rosácea (L25), fina y tamizada; barniz (L20), compacto y homogéneo. Pie muy bajo anguloso, con $5 \mathrm{~cm}$ de diámetro.

La pieza conserva la banda inferior de la pared decorada, a base de series de dos círculos concéntricos sogueados, con punto en el centro; el diámetro del círculo exterior es de 1'9 cm con el fondo; por la parte superior conserva las dos molduras de separación de la banda superior que también estaría decorada. Las series de círculos son un elemento muy repetido y estereotipado entre la producción hispánica. La forma 37
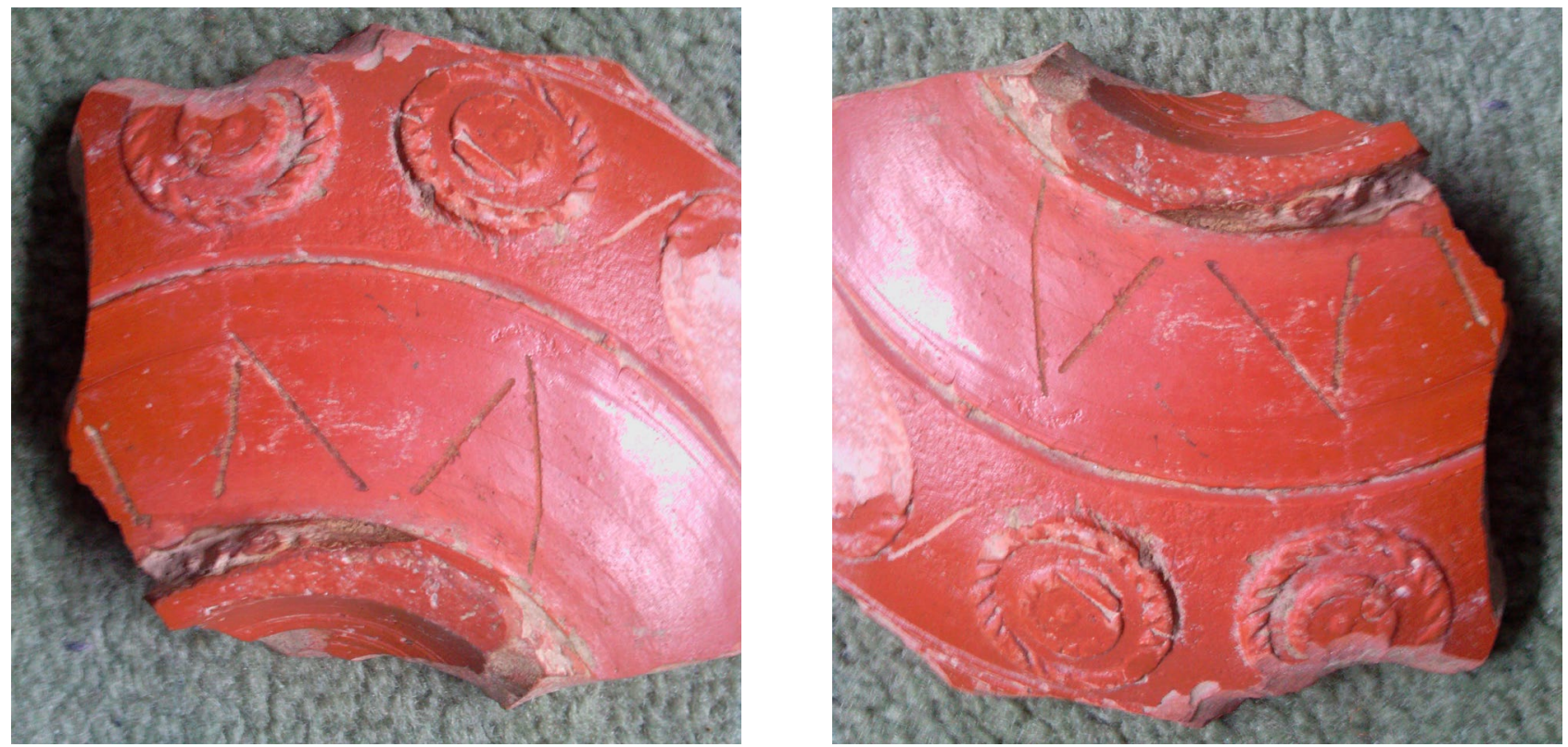

Figura 2: La inscripción orientada según sus dos posibles lecturas. 
es una de las más comunes entre la producción decorada; se fabrica a partir del decenio 60-70 d.C. y continúa su producción durante el siglo II; de hecho es una de las formas que más prolongará su fabricación pasando posteriormente a ser uno de los puntos de unión entre la fabricación de sigillata del Alto Imperio y la del Bajo Imperio o Hispánica Tardía. Por las características de pasta y barniz nos inclinamos a adjudicar una cronología probablemente dentro de finales del siglo I o principio del siglo II d.C.

Grafito externo: / AA ¿??? o $\mathrm{M}$ o bien VVL

\section{3)}

Fragmento de fondo y pie de 5'7 x $3 \mathrm{~cm}$. Pasta anaranjada fina (M49); barniz rojo muy claro (P37) con algo de brillo. El pie tiene una altura de 0 ' $2 \mathrm{~cm}$ y un diámetro de $6 \mathrm{~cm}$.

Tanto por la tipología, pie muy bajo, forma de cuenco, barniz con una cierta calidad, podría tratarse de un producto tardío de Sigillata Hispanica, dentro de los primeros tipos de esta variedad, en parte continuadora de la Terra Sigillata Hispanica del Alto Imperio. No disponemos del borde de la pieza, lo que dificulta su adscripción tipológica, no obstante en razón del perfil que conserva, lo incluimos dentro de los cuencos, en cierta forma derivados de la forma Hispánica 8 , del Alto Imperio (Juan, 1997, 556, fig. 6); para Palol es su tipo 10 (Palol y Cortés, 1974). La forma tiene su origen en la producción gálica tipo Ritterling 8 del que pasará a lo hispánico. Se trata de ver en la pieza que estamos tratando un producto dentro del siglo III d.C. No vamos a entrar en la complicada sistematización tipológica (Juan, 1997) que tiene esta variedad cerámica, sólo indicaremos que por lo que atañe a esta pieza sigue las líneas marcadas por las sigillatce hispánicas del Alto Imperio. En alguna ocasión se ha apuntado la posibilidad de la conformación de un servicio entre las formas Hispánica. 4 y 8 en período tardío (Palol y Cortés, 1974, 130-132, fig. 42; Romero Carnicero, 1983, 116, nota 48), cosa que no está clara en nuestra opinión. Nos encontramos, pues, ante una pieza tardía pero que tipológicamente es una continuidad de las del Alto Imperio, ahora con características definitorias tardías. Es uno de los tipos tardíos más numerosos.

Las repercusiones de la situación económica y política a partir del siglo III, produce una recesión general y por ello del consumo de productos. La Sigilata Hispánica del Alto Imperio sufre ese estancamiento. A partir de este momento habrá cambios en el producto sigillata, adaptaciones a nuevos y convulsos tiempos. La variación formal, las diferencias en cuanto a pastas y barnices, conformarán lo que se viene denominando Terra Sigillata Hispánica Tardía. Avanzado el siglo, hay una readaptación a un nuevo marco económico, a nuevas competiciones económicas, puesto que la llegada de nuevos productos procedentes del Norte de África, la Sigillata Clara en sus variedades, hace que los productores hispánicos reorganicen sus talleres,

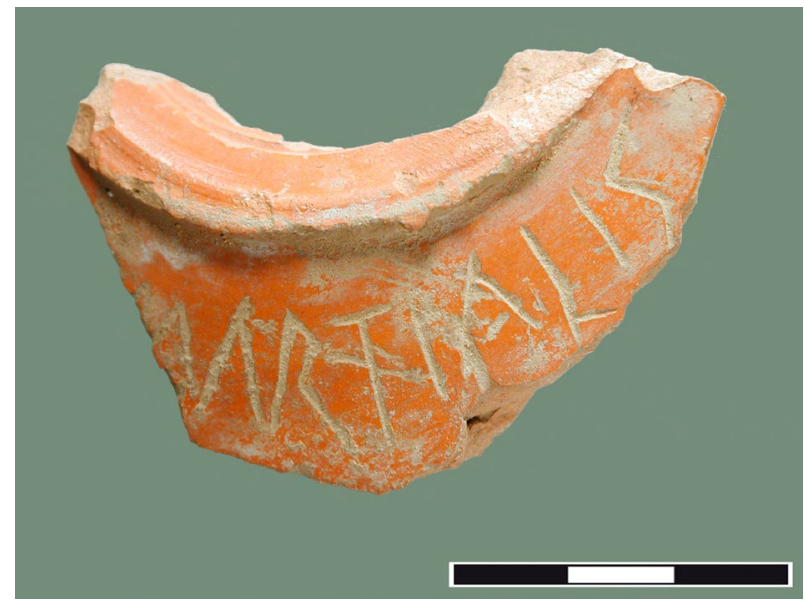

Figura 3: Fragmento de cerámica con grafito MARTIALIS.

sus tipos, sus ofertas de productos con tal de poder competir con nuevos tiempos y gustos. Hay una continuidad, como hemos indicado entre los productos del Alto Imperio y los del Bajo Imperio, fundamentalmente a través de algunas de sus formas, como son las hispánicas 1, 2, 4, 6, 8, 24/25, 37 y 77, entre otras. No sólo son productos del Norte de África, sino que a ellos se suman la competencia de los del sur de las Galias. Este panorama cambiante hace que los alfares hispanos ofrezcan unos productos adaptados a esos nuevos gustos. Estas cerámicas también cuentan con productos decorados (Mezquíriz, 1961, II, lám.129-137).

Grafito externo:

\section{MARTIALIS}

La pieza tiene muescas y rayas al interior, donde también ha saltado en parte el barniz.

Ya había sido localizado un MARTIALIS en grafito sobre Terra Sigillata Hispanica, en un vaso Hispánica 37 de Caesaragusta (Navarro y Magallón, 1994).

4)

Fragmento de fondo, pie y arranque de pared. De 5 x 4'9 cm, un diámetro de pie de $8 \mathrm{~cm}$. Pasta rosácea anaranjada (M55); barniz naranja muy claro y fina película (N59).

El pie es casi inexistente. Al carecer de pared y borde, dificulta la identificación tipológica. Por pasta y barniz pertenece a los productos de Terra Sigillata Hispánica Tardía, al igual que la anterior, no obstante, por sus características físicas le damos una cronología más tardía, ya dentro del siglo IV d.C. Poco a poco se ha ido avanzando en el conocimiento formal de esta variedad tardía, y al mismo tiempo sobre sus cronologías, si bien este no es un tema - ni mucho menos - todavía cerrado. Las excavaciones de ciertos yacimientos han permitido una aproximación a esta realidad tipológica y cronológica. Por ejemplo los vertederos de las villas de Relea (Saldaña) y la Serna 


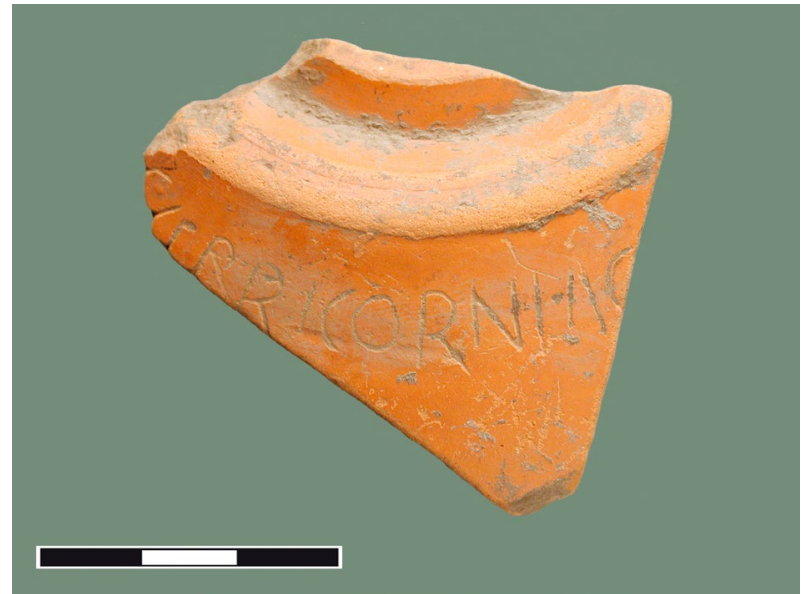

Figura 4: Fragmento de cerámica con grafito CAPRICORNI $A Q$.

(Palencia), mercado de abasto de Toledo (Juan et alii, 1995; Nozal et alii, 1995; cita de Juan, 1997, nota 46 de Carrobles y Rodríguez, 1988), entre otros.

En pared externa grafito:

\section{CIAPRICORNI·AQI}

Hay un vaso del taller de producción cerámica de La Maja en La Rioja, que tiene letras en relieve de los signos del zodiaco, entre ellos, un CAPRI[CORNIVS]. Es una variedad especial de cerámica con engobe negro y a molde, con una comercialización localizada regionalmente (Amante et alii, 1994).

El tema zodiacal también estuvo presente como distintivo de diversas legiones, en concreto Capricornio referido al signo del zodíaco de Augusto, a partir del cual son varias las que lo llevan en sus estandartes (Garcia-Bellido, 2004, 276). Su aparición incisa sobre una pieza cerámica tal vez la relacione con este mundo del ejército romano al que podría pertenecer su poseedor.

Entre la epigrafía romana nos encontramos con aquellas inscripciones que en lenguaje culto y sobre diversos materiales generalmente piedra o metal, y menos frecuentemente sobre madera o marfil, están realizadas para la difusión, propaganda, culto, política, para que sean visualizadas y leídas por los ciudadanos, a ellas la investigación ha dedicado una especial atención. Pero hay otros testimonios de inscripciones, más humildes y que en ocasiones han pasado desapercibidas para la investigación, son aquellas ejecutadas a mano, pintadas o incisas sobre diversas superficies como paredes y objetos, que en principio no estaban destinados para este menester. Se realizan en un lenguaje vulgar y coloquial, en el que evidentemente tiene mucho que ver en el resultado final los conocimientos y el nivel cultural de la persona que lo realiza. El transcurrir del tiempo ha destruido las ciudades y los muros donde se asentaban muchos de estos mensajes, ha hecho desaparecer los objetos, lo que ha supuesto la pérdida de una parte importante del paisaje de pensamiento, de costumbres, de expresiones del mundo antiguo. Pero las excavaciones arqueológicas, los hallazgos casuales sacan a la luz los fragmentos más humildes de esta expresividad, los realizados sobre cerámica. Este tipo de inscripciones, en colecciones y espacios amplios donde se ha estudiado, como es el caso de Italia y Grecia, se detectan desde el siglo VIII a.C., y van unidas indefectiblemente unidas a la aparición de la escritura (Agostiniani, 1982, 21).

Las que aquí estamos tratando son inscripciones realizadas sobre la superficie cerámica con el objeto ya finalizado, graffiti post coctionem, éstos aparecen con cierta frecuencia sobre cerámica romana y en diversos tipos, tanto cerámica común u otras variedades como en este caso terra sigillata. A otro tipo de grafitos pertenecen aquellos que se realizan antes de la cocción, generalmente relacionado con el proceso de producción, por lo que después del proceso de fabricación forman parte de la pieza como es el caso de las ánforas. Los nuestros se realizan, pues, con posterioridad a la cocción con un objeto en punta, con la dificultad añadida de hacerlo sobre una superficie curva, dura y engobada en el caso de la sigilata, lo que dificulta el trabajo y el resultado. En la Hispania romana es frecuente que los porcentajes de estos grafitos son más elevados sobre piezas de terra sigillata Hispani$c a$, que en los productos sudgálicos o itálicos, y sobre las otras variedades cerámicas. Varios pueden ser los motivos: desde los puramente estadísticos, a otros relacionados con el 'valor personal del objeto'(Mayet, 1983-84, 241; Ozcáriz, 2010, 333); sin perder de vista los niveles de alfabetización en cada momento así como la posibilidad de acceso a las diferentes variedades cerámicas de las diversas clases sociales (Ozcáriz y Unzu, 2011, 94). La única intención comunicativa es la referida al espacio y entorno del objeto, sin más trascendencia pública.

Generalmente se pueden distinguir diversos tipos en estos trazos a mano: los nominales, textos más amplios, signos y letras aisladas y los figurativos (Ozcáriz y Unzu, 2011). Veamos algunos ejemplos significativos de estas variedades que se localizan en Hispania:

Nominales- Son aquellos que identifican claramente al propietario de la pieza. Suelen escribirse en genitivo, aunque también los hay en nominativo.

Textos más extensos- Relativos al contexto de la pieza, a su función, dedicatorias, amenazas sobre robo, contenido... Son, sin lugar a dudas, de los más interesantes en cuanto a su significación. Se enmarcan en una amplia temática, tal como vemos a continuación.

- Los de carácter votivo o funerario. Como es el caso de la dedicatoria a Venus y al difunto en pieza de cerámica común de Sagunto (Corell, 1989).

- Los que indican función. En un grafito sobre jarra procedente de Calahorra: EUTYCHETIS PONE, 

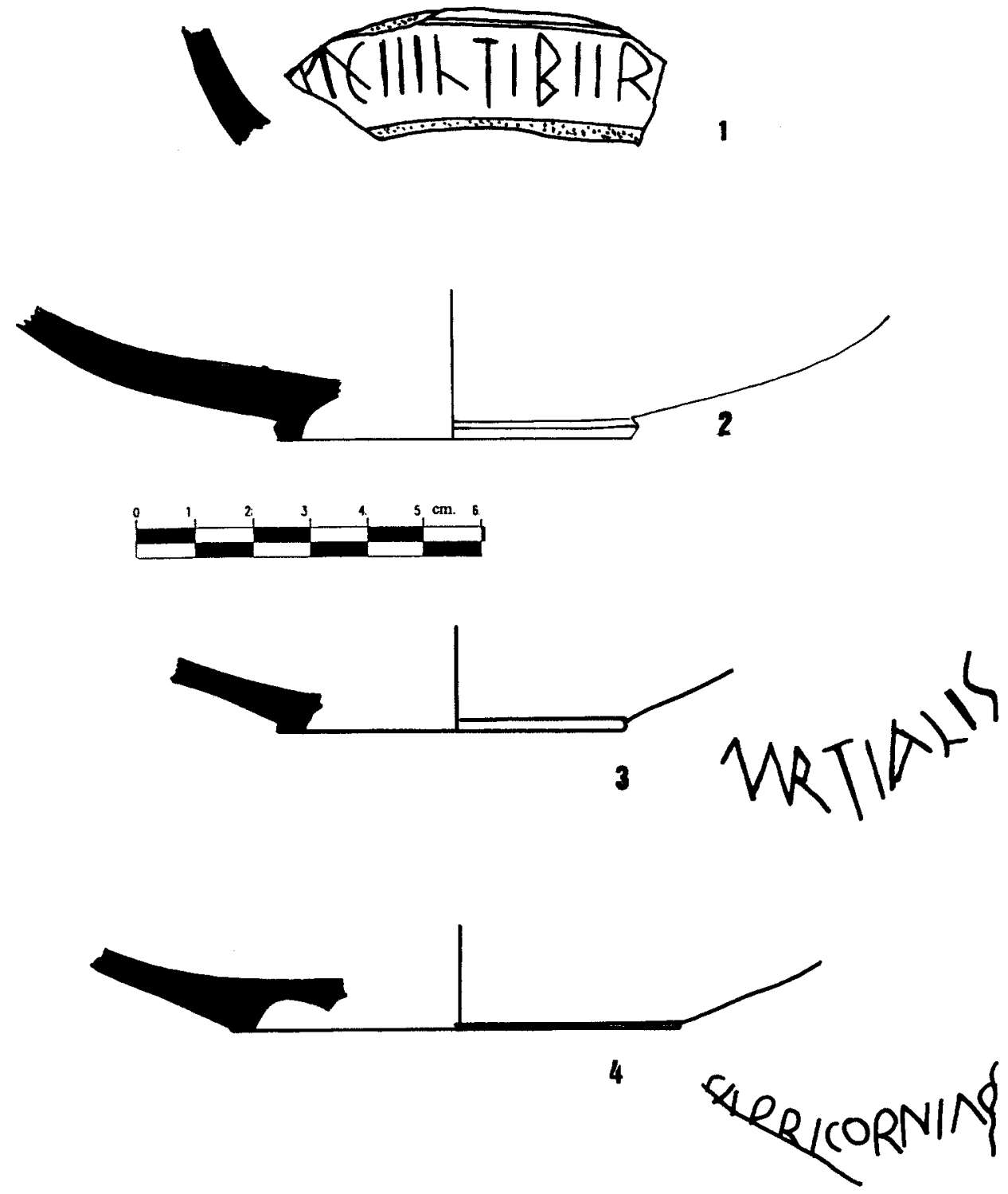

Figura 5: Dibujos de las cerámicas citadas en el texto.

(Eutiques pónme,o lléname Eutiques) (Luezas, 2009). Otro con una clara función, de un plato de forma hispánica 15/17 de Uxama en el fondo externo del cual escribieron: [I] HE LAVAPENIS, que parece indicar el posible uso de la pieza para la higiene de esa parte del cuerpo (García Merino et alii, 2010).

- Mal uso, protección, contra robo. Como por ejemplo la pieza que indica el uso único por parte de una persona a la que identifica en la inscripción y no de otra para la cual los deseos del propietario no son positivos, en esta ocasión sobre una pieza de cerámica procedente de la Serna (Palencia): SEV.../ARENI ANN.../A NN/CINEVS QVI LEERI T, del cual está clara la lectura de la última línea (marica el que lo robe) en esta ocasión la pieza es una sigillata Hispanica forma 8 (Robles y Cortés, 1968). Y la significativa: NOLI ME
TANGERE (no me toques) de pieza procedente de Italia, localizada en Sagunto (Montesinos, 1991, fig. 16, 14).

- Deseo, regalo. El grafito EYTYXEI (que seas feliz) de la casa de Hippolytus en Complutum, donde se confirma el hecho de que el conjunto de grafitos sobre terra sigillata Hispanica es el más importante del yacimiento por encima de las otras variedades cerámicas (Rascón et alii, 1994).

- Consejo, buenas costumbres. Es de sumo interés, en alguna ocasión, la referencia a la función del vaso y la llamada a la moderación en un argumento de buenas costumbres como es el grafito sobre pieza hispánica forma 27 procedente de Huete en la provincia de Cuenca, y que dice así: [....] (c) VI BIBIT HO(neste?) [....] CIT (cabeza femenina) QV(inti). Fl(lia) / [....] IRI CAT $<$ I $>$ LLI DECET IL(lo) [....] (cuya traducción es A quien bebe con 
moderación le sienta bien [] del [ ] vaso. Lo dice [ ] hija de Quinto) (Galiana y Ramos, 1987).

Signos y letras- De difícil lectura e identificación en algunos casos. Como forma y control de almacenaje, en referencia a la hornada, al transporte, en alguna ocasión podría referirse a abreviaciones del nombre del propietario.

Dibujos figurativos- Hojas, palmas, tridentes, personajes...en ocasiones alternando con textos y/o letras.

La seriación anterior se refiere fundamentalmente a la identificación de las características de los signos/significado de los grafitos, no obstante podemos aproximarnos a los mismos en un marco más amplio definiendo el modelo de inscripción tal como: nombre simple, nombre del propietario y del objeto y finalmente iscrizioni parlanti (Vavassori, 2012, 81). Como observamos la realización de textos sobre estos objetos en numerosas ocasiones pretenden clamar e identificar el objeto como de pertenencia a su propietario. Es el caso de las denominadas Iscrizioni parlanti en las cuales aparece una referencia al 'yo': ego, sum, me. (Agostiniani, 1982, 21). Si bien en nuestros casos no siempre se da la aparición de alguno de estos elementos, la realidad es que la referencia a 'pertenencia' está clara en la mayoría de ellos. Es mucho más clara en las que aparece el nombre del propietario junto a protección contra el mal uso o robo por cualquier otra persona, $y$ en aquella como la que dice: Noli me tangere.

De las cuatro piezas que aportamos, dos son claramente nominales en cuanto se refieren al propietario. Celtiber puede indicar «un origen tribal-geográficogentilicio, como un etnónimo o bien funcionando como cognomen, es decir como un atropónimo» (Ballester, y Turiel, 2013, 18). Antropónimo también la pieza con grafito Martialis, al igual que la número 2 de difícil lectura dado lo fragmentario, pero probablemente podría entrar dentro también de estas nominales.

La número 4, referida a un signo del zodíaco, podría indicar el signo del propietario o la fijación de un momento determinado, el de la compra, regalo de la pieza, o bien como hemos indicado más arriba a su referencia en un entorno del ejército romano.

Es evidente que el hecho de no tener datos sobre el lugar de hallazgo, estratigrafía y demás filiaciones que nos podían aportar una mayor significación e información tanto para el contexto de las piezas como para su cronología, nos obliga a establecer fechas a partir de la tipología de la pieza. Los estudios recientes de grafitos sobre cerámica en un mismo yacimiento puede aportar significativos datos, incluso una distribución por barrios y espacios de la ciudad y su entorno con diferentes funciones, tal como sucede en el yacimiento galo-romano de Bliesbruck (Moselle) (Trapp, 2007). Los últimos tiempos han supuesto un gran avance en la caracterización de estos productos culturales, a los que ha contribuido el estudio de conjuntos como el de Segóbriga, donde además se detecta nuevamente la abundancia de estos grafitos en la mayoría de las ocasiones sobre la vajilla doméstica sigilata (Abascal y Cebrián, 2007).

Estos pequeños fragmentos de escritura son tenidos en cuenta por los corpora sobre epigrafía romana, por lo que nos aportan sobre la vida cotidiana, sobre la lengua y la escritura, propiedad, costumbres, prácticas comerciales o religiosas, y no de las élites sino de las clases menos influyentes. Tuvieron una aparición paralela a la de la escritura y gozan de gran éxito e todos los espacios linguisticos de la Antigüedad (Agostiniani, 1982, 271). En suma una aproximación a la vida cotidiana, a la historia económica y social de los diversos lugares del imperio, así como información sobre las personas que saben leer y escribir (Trapp, 2007, 7). Nos proporcionan información sobre la lengua vulgar, incluso en ocasiones con errores ortográficos y de composición, lo que nos aproxima a la realidad de la vida cotidiana, transmitiéndonos una lengua viva y expresiva, aportándonos fenómenos lingüísticos difícilmente identificables en los textos «oficiales» 0 «cultos».

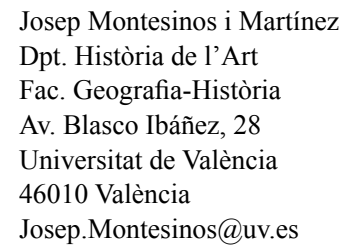

\section{BIBLIOGRAFÍA}

ABASCAL, J.M., CEBRIÁN, R., 2007: «Grafitos cerámicos de Segóbriga (1997-2006)», Lvcentvm, XXVI, 127-171.

AGOSTINIANI, L., 1982: Le «iscrizioni parlanti» dell'Italia antica, Lingue e iscrizioni dell'Italia antica 3, Firenze.

AMANTE, M., MARTÍNEZ, M. y GONZÁLEZ, A., 1994: «El alfar de La Maja abre los secretos de su biblioteca: comienzan a aparecer masivamente los fragmentos cerámicos con inscripciones del alfarero G. Valerio Verdulo (Campaña de excavaciones de agosto de 1995)», Estrato: Revista riojana de arqueología, 6, 37-47.

BALLESTER, X. y TURIEL, M., 2013: «CAPRICORNI, CELTIBER, MARTIALIS y Otros Textuelos Hispanorromanos», Elea, 13, 11-30.

CARROBLES, J. y RODRÍGUEZ, S., 1988: Memoria de las excavaciones del solar del nuevo mercado de abasto (poligono industrial, Toledo). Introducción al estudio de la ciudad de Toledo en el siglo IV d.C., Diputación Provincial.

CORELL, J., 1989: «Grafito sobre vaso de cerámica hallado en Sagunto», Arse, 24, Sagunto.

DELGADO, M., MAYET, F. y MOUNTINHO DE ALARÇAO, A., 1975: Fouilles de Conimbriga IV. Les Sigillées, Paris. 
GALIANA, M.F. y RAMOS, M.L., 1987: «Una copa Drag. 27 con grafitos procedente de Huete (Cuenca)», Lucentum, VI, 135-138.

GARABITO, T., 1978: Los alfares romanos riojanos, Bibliotheca Praehistorica Hispana XVI, Madrid.

GARCÍA-BELLIDO, M.P., 2004: Las legiones hispánicas en Germania. Moneda y ejército, Anejos de Gladius, Madrid.

GARCÍA MERINO, C., BALADO, A. y MARTINEZ, A.B., 2010: «Grafito sobre sigillata hispánica con el hapax lavapenis», BSAA, LXXVI, 161-170.

JUAN TOVAR, L.C., 1997: «Las industrias cerámicas hispanas en el Bajo Imperio. Hacia una sistematización de la Sigillata Hispánica Tardía», Congreso Internacional, La Hispania de Teodosio, vol. 2, 543-568, Salamanca.

JUAN TOVAR, L.C., PÉREZ, C. y FERNÁNDEZ, C., 1995: «Un vertedero del siglo IV d.C. en Relea (Saldaña). Campaña 1985», III Congreso de Historia de Palencia, t. I, 381-400, Palencia.

LORRIO, A., 2011 «Los celtas en el occidente de Iberia», en G. RUIZY J. ÁLVAREZ-SANCHIS (Eds.), Castros y verracos de la Edad del Hierro en el occidente de Iberia, 45-100, Ávila.

LUEZAS, R.A., 2009: «Una jarra de cerámica romana con inscripción post coctvram del Museo de la romanización en Calahorra», Kalakorikos, 14, 213-226.

MAYET, F., 1983-1984: Les céramiques sigillées hispaniques contribution à l'histoire économique de la Péninsule Ibérique sous l'Empire Romain, dos vols, Paris.

MEZQUÍRIZ, M.A., 1961: Terra Sigillata Hispanica, vols. I y II, Valencia.

MEZQUÍRIZ, M.A., 1958: «La excavación estratigráfica de Pompaelo. Campaña 1956», Excavaciones en Navarra VII, Pamplona.

MONTESINOS, J., 1991: Terra Sigillata en Saguntum y tierras valencianas, Sagunto.

MONTESINOS, J., 1998: Terra Sigillata en Ilici, Serie Arqueológica 16, Real Academia de Cultura Valenciana, Valencia.
NAVARRO, M. y MAGALLÓN, M. A., 1994: «Un nuevo grafito Cesaraugustano», Boletín Museo Zaragoza, 13, 295-302.

NOZAL, M., PUERTAS, M. y RÍOS, D., 1995: «La villa romana de 'Los Moros'. La Serna (Palencia). Trabajos de prospección y sondeo», III Congreso de Historia de Palencia, t. I, Palencia.

OZCÁRIZ, P., 2010: «Grafitos epigráficos sobre cerámica romana en Navarra», Cuadernos Arqueología Universidad de Navarra, 18**, 331-354.

OZCÁRIZ, P. y UNZU,M., 2011: «Grafitos figurativos, palmas, tridentes y otros signos en cerámica romana de la plaza del Castillo de Pamplona», VII Congreso General de Historia de Navarra, v. I, Príncipe de viana, núm 253, 79-95.

OSWALD, F. y PRYCE, T.D., 1920: An Introduction to the Study of Terra Sigillata, London.

PALOL, P. de y CORTÉS, J., 1974: La villa romana de La Olmeda, Pedrosa de la Vega (Palencia). Excavaciones de 1969 y 1970, I, Acta Arqueológica Hispánica 7, Madrid.

RASCÓN, S., POLO, J. y MAESO, M.D., 1994: «Grafitos sobre terra sigillata hispánicas hallados en un vertedero del siglo I en la casa de Hippolytus (Complutum)», Cuadernos de Prehistoria y Arqueología Universidad Autónoma de Madrid, 21, 235-270.

ROBLES, J. Ma. y CORTÉS, J., 1968: «Grafito sobre terra sigillata encontrado en la villa romana de La Serna (Palencia)», Publicaciones de la Institución Tello Téllez de Meneses, 49, 5-17,.

ROMERO CARNICERO, M.V., 1983: «Aspectos formales de la sigillata hispánica», Boletín del Seminario de Estudios de Arte y Arqueología, 49, 105-134.

TRAPP, J., 2007: «Les graffites sur céramique de l'agglomeration gallo-romaine de Bliesbruck (Moselle) (Ier-IVe siècle après J.-C.», Les Cahiers Lorrains, 1-2, 7-15.

VAVASSORI, M., 2012: «La personalizzazione della ceramica domestica», Sylloge Epigraphica Barcinonensis, X, 81-99. 